Geociências

\title{
Identificação e Classificação do relevo do município de São Martinho da Serra - RS
}

\author{
Studies and Geomorphological Classification of São Martinho da Serra \\ - RS
}

\author{
Antonio Von Ende Dotto' ${ }^{(1)}$, Luís Eduardo de Souza Robaina ${ }^{1(i)}$ \\ ' Universidade Federal de Santa Maria, Santa Maria, RS
}

\section{RESUMO}

O relevo é um dos principais definidores das unidades ambientais, de modo que sua compartimentação se apresenta com estreita relação à distribuição dos demais atributos de gênese da paisagem. $\mathrm{O}$ objetivo desse estudo é estabelecer uma compartimentação do relevo do município de São Martinho da Serra, Rio Grande do Sul, com a utilização de bases cartográficas em formato digital associadas ao Sistema de Informação Geográfica, através de métodos automatizados e com integração de variáveis morfométricas. Para definição das formas de relevo foi considerado a análise combinada dos atributos morfométricos amplitude e declividade identificando áreas planas, colinas suaves de altitude, colinas onduladas, associação de colinas com morros e morrotes e morrotes isolados. Os elementos do relevo foram obtidos através da técnica automática que consiste na análise do nível de cinza de uma célula central e as suas vizinhas, determinando diferenças topográficas. Os elementos identificados são planos, picos, cristas, ressaltos, cristas secundárias, encostas ou vertentes, escavados, base de encostas, vales e fossos. Para a classificação das formas das vertentes, utilizou-se o perfil e plano de curvatura das vertentes, definindo 4 unidades geomorfométricas definidas como Unidade I convexo-convergente, unidade II côncavo-convergente, unidade III convexo-divergente e unidade IV côncavo-divergente. De forma geral, a metodologia empregada obteve resultados satisfatórios, permitindo uma análise rápida e consistente do relevo do município.

Palavras-chave: Estudos ambientais; Geotecnologias; Geomorfologia

\section{ABSTRACT}

The relief is one of the main definers of the environmental units, so that its compartmentalization is closely related to the distribution of the other attributes of landscape genesis. The objective of this study is to establish a division of the relief of the municipality of São Martinho da Serra, Rio Grande do Sul. Cartographic bases in digital format associated with the Geographic Information System were used, 
through automated methods and with the integration of morphometric variables. For the definition of the relief forms, the combined analysis of the morphometric attributes amplitude and slope was considered, identifying flat areas, gentle hills of altitude, rolling hills, association of hills with large hills and buttes and isolated buttes. The relief elements were obtained through the automatic technique that consists of the analysis of the gray level of a central cell and its neighbors, determining topographic differences. The identified elements are flat, peak, ridge, shoulder, spur, slope, hollow, footslope, valley and pit. For the classification of the forms of the slopes, the profile and plane of curvature of the slopes were used, defining 4 geomorphometric units defined as Unit I convex-convergent, Unit II concaveconvergent, Unit III convex-divergent and Unit IV concave-divergent. In general, the methodology used obtained satisfactory results, allowing a quick and consistent analysis of the relief of the municipality.

Keywords: Environmental studies; Geotechnologies; Geomorphology

\section{INTRODUÇÃO}

Na ciência geográfica, destaca-se a importância do estudo do relevo, que, segundo Casseti (1991) tem uma forte relação com as ações humanas, seja na sua locomoção, construção civil, cultivos, dentre outros domínios. Portanto, refere-se não somente a morfologia (forma) mas também a sua fisiologia (função). Isso indica que a apropriação da superfície terrestre pelas ações antrópicas, devido à urbanização ou expansão de atividades econômicas, influencia na dinâmica superficial terrestre. As diferentes formas de relevo presentes na superfície terrestre são oriundas da interação entre processos tectônicos, pedogênicos e intempéricos, que atuam de forma diversificada nos diferentes materiais rochosos (LANA, 2001).

Conforme Ross (2014), não existe nada de mais concreto do que as formas da superfície terrestre, no entanto, elas só existem enquanto geometria e não enquanto elemento concreto. Estudos sobre o relevo de determinada região permite compreender a ação de processos superficiais como erosão, movimentos de massa e pedogênese. Além disso, indica condições de fragilidade relacionado ao uso do solo. Desta maneira, a análise do relevo insere-se nos estudos ambientais, contribuindo para orientar a instalação das atividades humanas (CHRISTOFOLETTI, 2001). Disserta Minar e Evans (2008), que a análise digital do relevo tem como grande desafio suprir a falta de precisão e objetividade dos 
mapeamentos geomorfológicos tradicionais. Nesse contexto, as tecnologias do Sensoriamento Remoto e Sistemas de Informações Geográficas (SIGs), se configuram como subsídios primordiais e não soluções (MELO et al. 2016). Para Melo (2016) as geotecnologias do sensoriamento remoto e SIG possibilitam a mensuração/estimativa e modelagem dos dados geoespaciais, permitindo a confecção de produtos cartográficos de múltiplas escalas. Assim, com a utilização de tecnologias de geoprocessamento, a morfometria do relevo tornou-se mais eficaz e prática para realização desses tipos de estudo.

A aplicação de técnicas digitais foram utilizadas em diversos trabalhos, citase: a classificação morfológica da República do Uruguai por Silveira e Silveira (2014); nos mapeamentos geomorfométricos desenvolvidos por Lange e Silveira (2015), em Blumenau/SC; Bortolini et al. (2017), na região sudoeste do estado do Paraná; Scotti et al. (2015) Furlan et al. (2018a), Trentin e Robaina (2016;2018) e Rademann et al. (2019) na compartimentação geomorfométrica de bacias hidrográficas e de municípios no Rio Grande do Sul. Além disso, destaca-se a utilização dos elementos do relevo, como cristas, vales e vertentes, classificados automaticamente, para compartimentação do relevo nos trabalhos de Robaina et al. (2016), Robaina et al. (2017), Silveira et al. (2018) e o trabalho de Furlan et al. (2018b).

O presente trabalho tem como finalidade identificar e classificar, utilizando técnicas digitais, o relevo do município de São Martinho da Serra a partir 3 níveis de observação definido como: formas de relevo representadas por áreas planas, colinas, morrotes e morros; elementos do relevo determinado por cristas, encostas, vales, etc; e o terceiro nível de classificação representa as formas das vertentes, baseado na inclinação, no plano e no perfil.

\subsection{Caracterização do Município}

Na região central do Rio Grande do Sul, está localizado o município de São Martinho da Serra (Figura 1) que é representado pela unidade geomorfológica do 
Planalto das Missões entre os modelados de Patamares do Planalto e o Rebordo do Planalto, que apresentam sua origem ligada ao vulcanismo que cobriu os sedimentos da Bacia do Paraná no final do Mesozóico (ROBAINA et al 2010). Seu substrato litológico é com predominância de rochas ígneas da Formação Serra Geral, porém, nas menores altitudes afloram os arenitos de granulometria grossa a fina, frequentemente com clastos de argila, com estratificação cruzada, designados da Formação Caturrita (WILDNER, 2006).

De acordo com Nimmer (1977), o clima é do tipo Mesotérmico Brando que domina a maior parte do Rio Grande do Sul. O inverno é pouco intenso, quando comparado com as regiões de maiores altitudes do Estado, enquanto que o verão é quente com médias mensais de janeiro acima de $22^{\circ} \mathrm{C}$. Os índices pluviométricos anuais situam-se entre 1.500 e 1.750 mm, com ausência de estação seca durante o ano.

O município está inserido na região hidrográfica do Uruguai (SEMA, 2017), na porção nordeste da Bacia Hidrográfica do Rio Ibicuí, a qual situa-se predominantemente no Centro-Oeste do Estado do Rio Grande do Sul que compõe uma drenagem que tem controle estrutural representados por contatos retos entre canais caracterizando um predomínio do padrão retangular.

Na região em que o município se encontra, se caracteriza por estar inserida na transição do Bioma Pampa e Mata Atlântica e a vegetação está no limite da Floresta Estacional Decidual e Campos Sul-Rio-grandenses (BAUERMANN et al., 2008).

A área de estudo faz limite com o município de Santa Maria ao Sul, São Pedro do Sul ao Sudoeste, Itaara ao Sudeste, Quevedos ao Noroeste e Júlio de Castilhos ao Norte e Nordeste. A área do território municipal possui cerca de 670,7 km² entre as seguintes coordenadas geográficas: $29^{\circ} 36^{\prime} 37^{\prime \prime} \mathrm{S}, 54^{\circ} 05^{\prime} 59^{\prime \prime} \mathrm{W}, 2^{\circ} 20^{\prime} 33^{\prime \prime} \mathrm{S}$, $53^{\circ} 41^{\prime} 15^{\prime \prime} \mathrm{W}$. 
Figura 1 - Mapa de Localização de São Martinho da Serra - RS

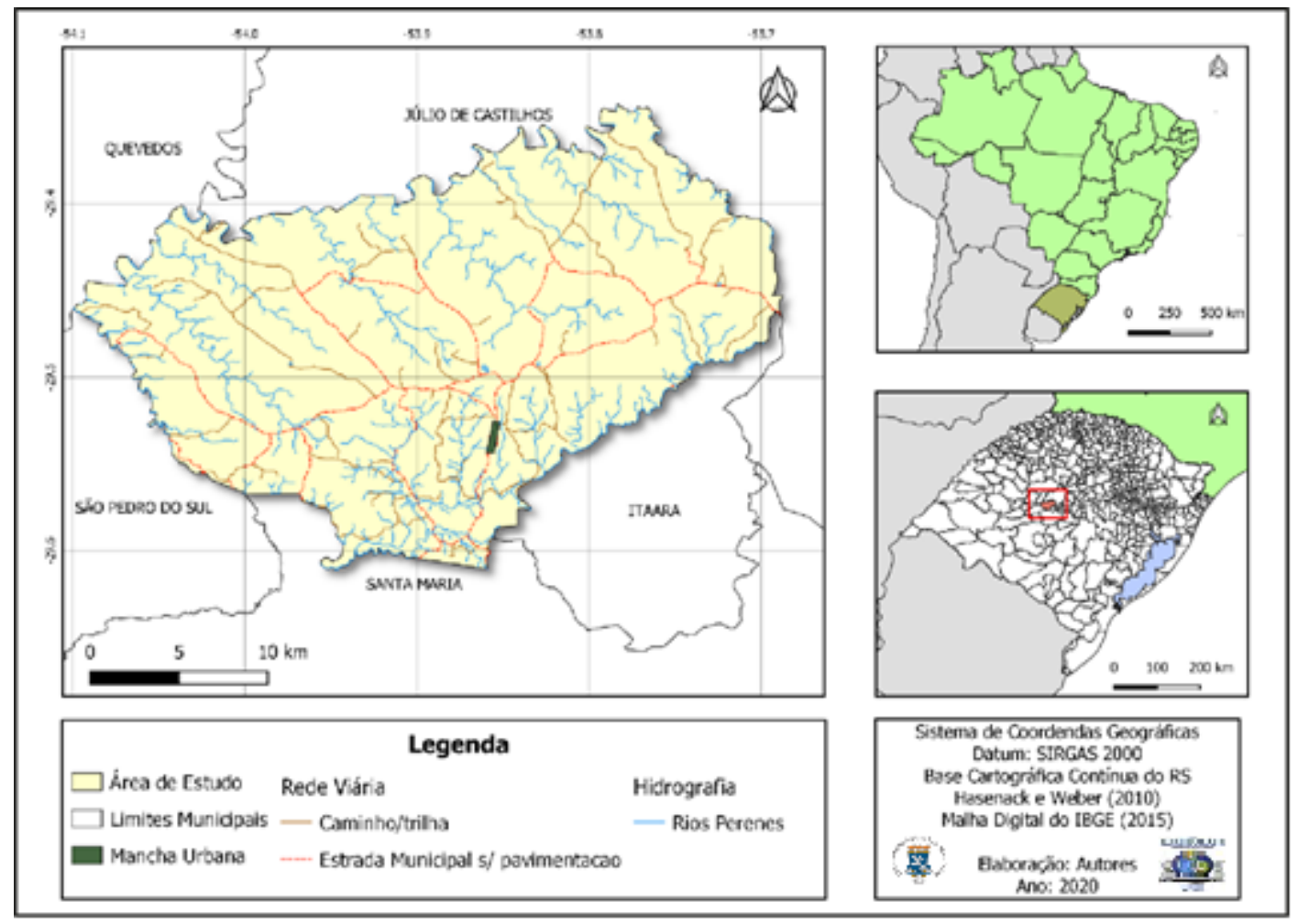

\section{METODOLOGIA}

A parte inicial do trabalho definiu o referencial teórico e metodológico através de pesquisa bibliográfica. A base cartográfica utilizada para os processamentos dos atributos morfométricos, foi o Modelo Digital de Elevação originado da missão Shuttle Radar Topography Mission (SRTM), com resolução espacial de 3 arc-second (90 metros). Os dados reprocessados com correção de erros NASADEM, estavam disponíveis para a resolução do MDE da área de estudo. O NASADEM (USGS, 2020) estende o legado da missão de topografia do radar de transporte (SRTM), melhorando a precisão das alturas no modelo digital de elevação (DEM) e cobertura de dados. Ele também fornece produtos de dados adicionais relacionados ao radar SRTM, atualizando o reprocessamento dos dados de sinal de radar SRTM original e dados de telemetria com algoritmos atualizados e dados auxiliares indisponíveis no momento do processamento SRTM original. No entanto, quando os produtos foram processados anomalias significativas foram 
encontradas em áreas planas. Para o limite municipal de São Martinho da Serra e outros municípios ao redor foi utilizado o banco de dados do IBGE, na malha digital do ano de 2015, e acrescentado o sistema viário e a hidrografia obtidas através da base cartográfica vetorial na escala 1:50.000 organizada por Hazenack e Weber (2010). Para a elaboração de mapas temáticos e análise de dados georreferenciados, empregou-se os softwares de SIG (Sistemas de Informação Geográfica), QGis 2.18.24 e ArcGis 10.5.

A análise da hipsometria foi realizada a partir do processamento de raster em que se obtêm o histograma de frequência e seus valores. Foram estabelecidas 5 classes: $<150$ m; 150 - 250 m; 250 - 350 m; 350 - 450 m; > 450 m. Tais classes foram postas de 100 em 100 metros para melhor classificação do relevo, visto sua elevada amplitude altimétrica.

As declividades e formas de relevo utilizadas foram adaptadas do Instituto de Pesquisas Tecnológicas do Estado de São Paulo (IPT, 1981). O limite de 2\% representa áreas planas, que quando associadas a rede hidrográfica, os principais processos geomorfológicos estão ligados a inundação e deposição; o limite de 5\% marca o início dos processos erosivos e; $15 \%$ que representa um limite onde movimentos de massa podem se constituir como processos em encosta e, além disso, impedem a mecanização da agricultura.

Para definição das formas de relevo foi considerando a análise combinada dos atributos morfométricos da área de São Martinho da Serra. Com base nisso, utilizou-se como referência a proposta de classificação do relevo do Instituto de Pesquisas Tecnológicas (IPT, 1981), conforme representa a Tabela 1, sendo essa proposta modificada e adaptada. 
Tabela 1 - Classificação das formas de relevo adaptado do (IPT 1981)

\begin{tabular}{lcc} 
Amplitude Altimétrica & Declividade & Formas de relevo \\
\hline & $<2 \%$ & Áreas Planas \\
& $2-5 \%$ & Colinas suaves \\
$<100$ metros & 5 a $15 \%$ & Colinas \\
& $>15 \%$ & Morrotes \\
$>100$ metros & $>15 \%$ & Morros \\
\hline
\end{tabular}

A partir da análise dos mapas de declividade e hipsometria com o efeito hillshade, que possibilita a visualização do relevo sombreado, foi realizada a vetorização manual para determinar as cinco formas de relevo: áreas planas, colinas suaves de altitude, colinas onduladas, associação de morros e morrotes e morros isolados.

Foi possível traçar os perfis topográficos com a ferramenta interpolate line e Profile Graph disponíveis no modulo 3D Analyst do ArcGIS 10.5. Em seguida, os perfis foram adaptados através do software CorelDRAW Graphics Suite 2017 desenvolvido pela Corel Inc., com o objetivo de aprimoramento do layout final.

Os elementos do relevo foram obtidos através da técnica de Jasiewicz \& Stepinski (2013), em que procuram compreender a similaridade textural do MDE, que consiste na análise do nível de cinza de uma célula central e as suas vizinhas, portanto quando a célula central obtiver valor igual assuma o valor " 0 ", quando assumir valor maior considera-se o valor de "1", e quando menor representa valores menores que "-1". A aplicação utilizada é online, disponibilizada no endereço eletrônico <<http://sil.uc.edu/geom/app>>. O código da aplicação também está disponível para baixar em http://sil.uc.edu, podendo ser implementada no ambiente do software SAGA. O arquivo de entrada para a varredura é um MDE. Os dois parâmetros livres são search radius (distância em metros ou célula unidades) e flatness (nivelamento em graus) e aplicou-se valor 
igual a 22 pixels na escala de comprimento para o elemento de relevo ser reconhecido e graus igual a $1^{\circ} \mathrm{em}$ que foi o melhor valor do ângulo determinado.

Assim, os elementos do relevo foram definidos em 10 classes com o processamento de MDEs do município: planos (flat), pico (peak), crista (ridge), ressaltos (shoulder), crista secundária (spur), encosta ou vertente (slope), escavado (hollow), base de encosta (footslope), vales (valley), e fosso (pit). Em ambiente SIG foram espacializados os geomorphons em um mapa temático e utilizado o Basemap - World Imagery do ArcGIS® 10.5 e também pelo software Google Earth Pro.

Para a classificação das formas das vertentes, utilizou-se o perfil e plano de curvatura das vertentes, definindo 4 unidades geomorfométricas por meio do cruzamento de informações e variáveis gerados através do SIG ArcGis 10.5.

\section{RESULTADOS E DISCUSSÕES}

As cotas altimétricas no município variam de 140 até 524 metros (Figura 2), resultando em uma amplitude altimétrica de 384 metros, o que representa um relevo com bastante energia devido as grandes diferenças de altimetria.

A Figura 2 apresenta a hipsometria do município com 5 classes, em que se pode observar que as altitudes predominantes se encontram entre o intervalo de 350 a 450 metros o que corresponde a 46,69\% com 333,25 km² de área.

As altitudes superiores a 450 metros correspondem a 23,95\% com 160,62 $\mathrm{km}^{2}$ da área e estão distribuídas, principalmente, na região Centro-Leste do município, que constituem áreas de divisores de água que delimitam bacias hidrográficas que drenam o município.

As áreas de menores altitudes, entre 150 e 250 metros e inferior a 150 metros estão localizadas no extremo Sul, caracterizando no total, $9,52 \%$ do município com $63,82 \mathrm{~km}^{2}$. Na tabela 01 é encontrada informações mais detalhadas da quantificação desses dados. 
Figura 2 - Mapa da hipsometria de São Martinho da Serra - RS

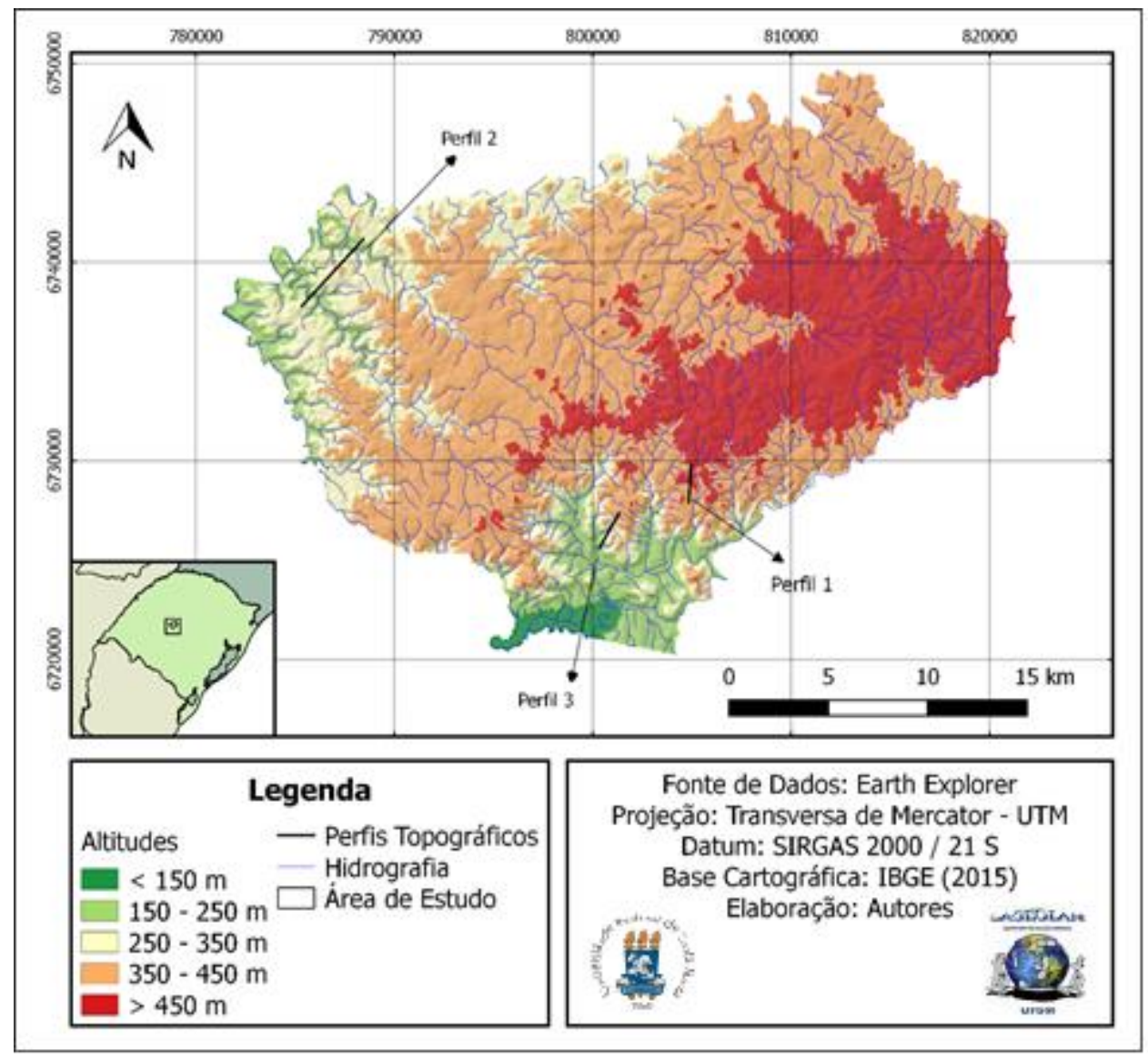

Tabela 2 - Dados quantitativos referentes às altitudes do município

\begin{tabular}{lcc}
\hline Classes $(\mathbf{m})$ & Área $\left.\mathbf{( k m}^{\mathbf{2}}\right)$ & Porcentagem (\%) \\
\hline$<150$ & 8,354 & 1,25 \\
$150-250$ & 55,465 & 8,27 \\
$250-350$ & 113,027 & 16,85 \\
$350-450$ & 333,253 & 49,69 \\
$>450$ & 160,624 & 23,95 \\
\hline
\end{tabular}

O intervalo de declividade predominante é entre 5 a 15\% que corresponde a quase metade da área de estudo, 46,65\% com 305,045 km² no território. Esse intervalo representa os locais onde os processos erosivos passam a atuar mais intensamente podendo gerar feições superficiais lineares com sulcos e ravinas. 
O intervalo de declividade menor de $2 \%$ compõe 9,94\% da área do município com $64,979 \mathrm{~km}^{2}$, que se distribui em sua maioria nos relevos de planícies, ocorrem os processos de acumulação que favorece o desenvolvimento de atividades agrícolas nas planícies de inundação como o cultivo do arroz irrigado.

Tabela 3 - Dados quantitativos referentes às declividades do município

\begin{tabular}{lcc}
\hline Classes & Área $\left.\mathbf{( k m}^{\mathbf{2}}\right)$ & Porcentagem (\%) \\
\hline$<2 \%$ & 64,979 & 9,95 \\
$2-5 \%$ & 186,445 & 28,51 \\
$5-15 \%$ & 305,045 & 46,65 \\
$>15 \%$ & 97,483 & 14,90 \\
\hline
\end{tabular}

Figura 3 - Mapa de declividade de São Martinho da Serra - RS

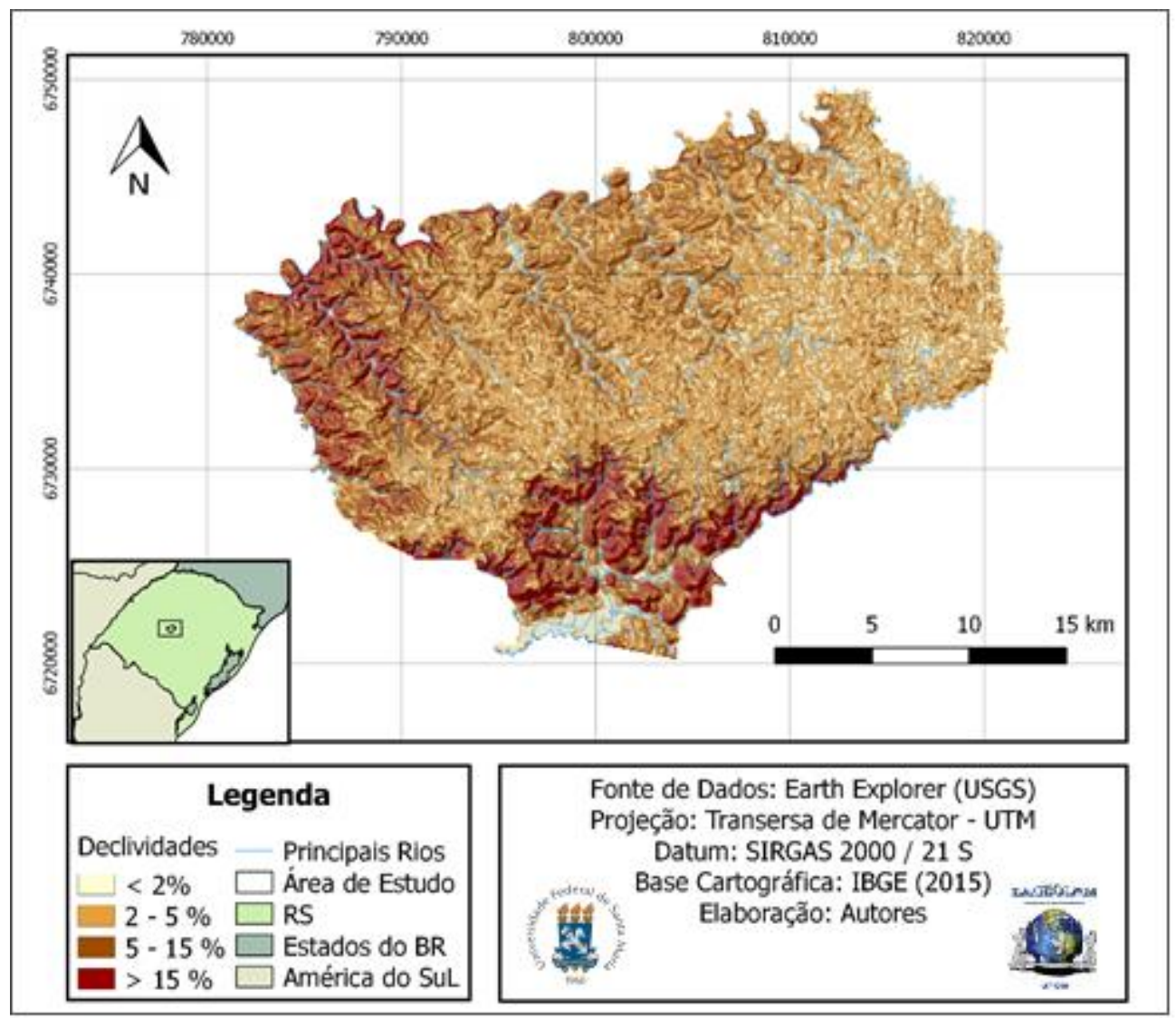

As declividades entre 2 a 5\% ocupam 28,51\% com 186,445 km² do território sendo caracterizadas por serem suavemente onduladas, essa declividade tem um 
fator econômico importante nas atividades agropecuárias visto que esse setor é relacionado diretamente pela ação geomorfológica do relevo com a perenidade (direta e indireta) dos cursos d'água.

Presente em 14,90\% do município em 97,483 km², as declividades superiores a 15\% representam as áreas de maior inclinação, marcando importantes rupturas de relevo encontradas nas vertentes da área do Rebordo do Planalto.

A amplitude das vertentes foi analisada a partir de perfis topográficos traçados em diferentes localizações no município, que podem ser encontrados no mapa hipsométrico (Figura 2).

O primeiro perfil topográfico da Figura 4 foi traçado ao Sudeste do município (Figura 2), próximo da área urbana, em um corte transversal de sentido Norte a Sul. Representa o aspecto de relevo mais comum, suavemente ondulado onde as amplitudes estão entre $20 \mathrm{~m}$ e $40 \mathrm{~m}$.

Figura 4 - Perfil topográfico de um relevo suavemente ondulado

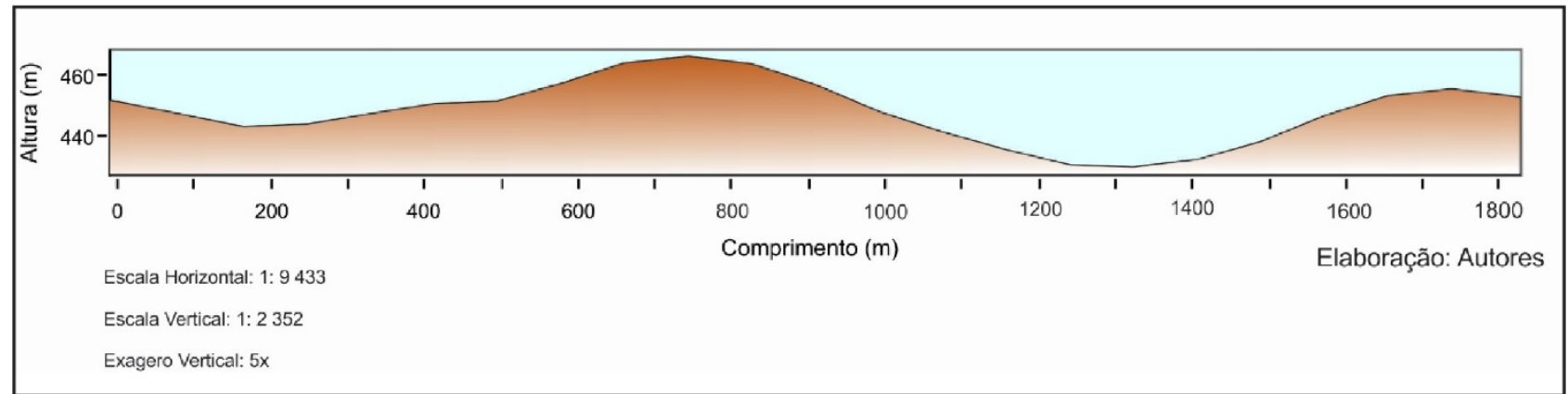

O segundo perfil traçado está apresentado na Figura 5, localiza-se entre o Arroio Lajeado da Esperança e o Arroio da Encrenca, na porção Leste do município (Figura 2). Ambos arroios escoam suas águas para o Rio Toropi, que constitui limite municipal entre São Martinho da Serra e Quevedos. O perfil apresenta comprimento próximo a 4.000 metros com relevo fortemente ondulado e amplitudes que variam de 60 metros a 120 metros, características das associações de morros e morrotes. 
Figura 5 - Perfil topográfico de um interflúvio

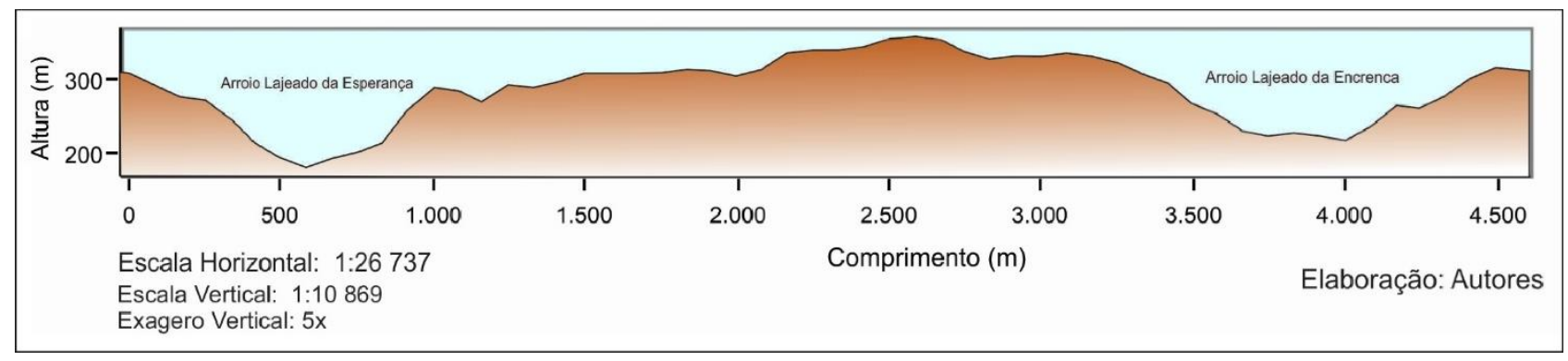

O terceiro perfil, da Figura 6, é traçado na porção Oeste do município (Figura 2) com comprimento de 2.500 metros, marca uma zona de transição geomorfológica da Depressão Periférica para o Rebordo do Planalto, com declividades acima de $15 \%$ e amplitudes superiores a 100 metros.

Figura 6 - Perfil topográfico de transição de compartimentação geomorfológica

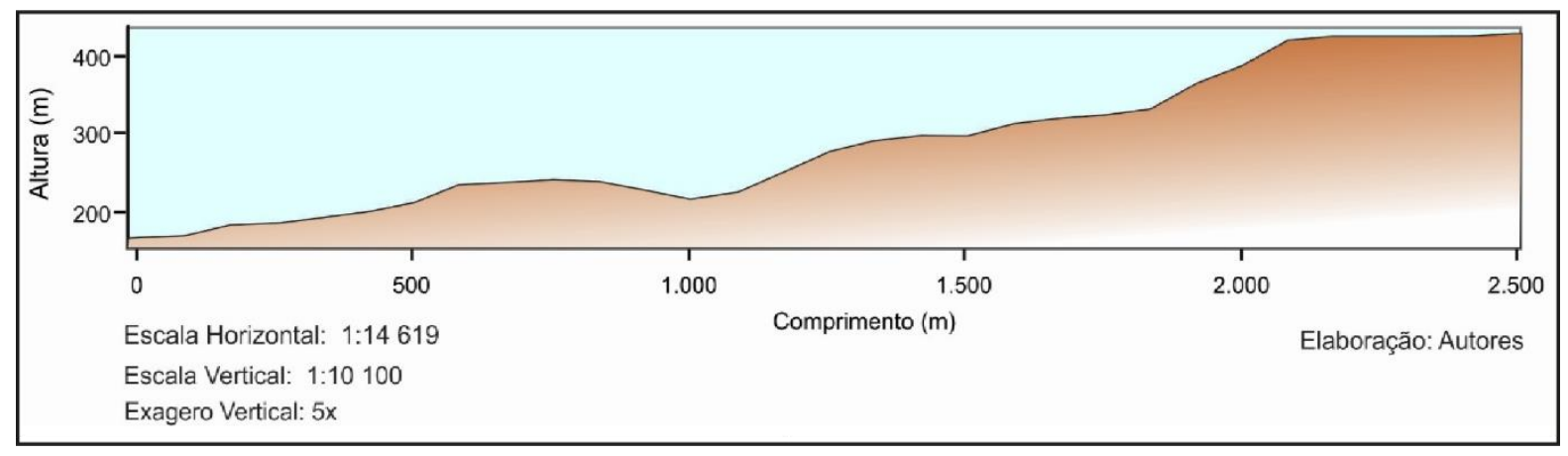

\subsection{Classificação das Formas de Relevo}

As altitudes observadas, parâmetros de declividade e amplitude das vertentes permitiu definir 5 formas para o relevo no município de São Martinho da Serra: áreas planas, colinas suaves de altitude, colinas onduladas, associação de colinas com morros e morrotes e morros isolados (Figura 7). 
Figura 7 - Mapa das formas de relevo de São Martinho da Serra -RS

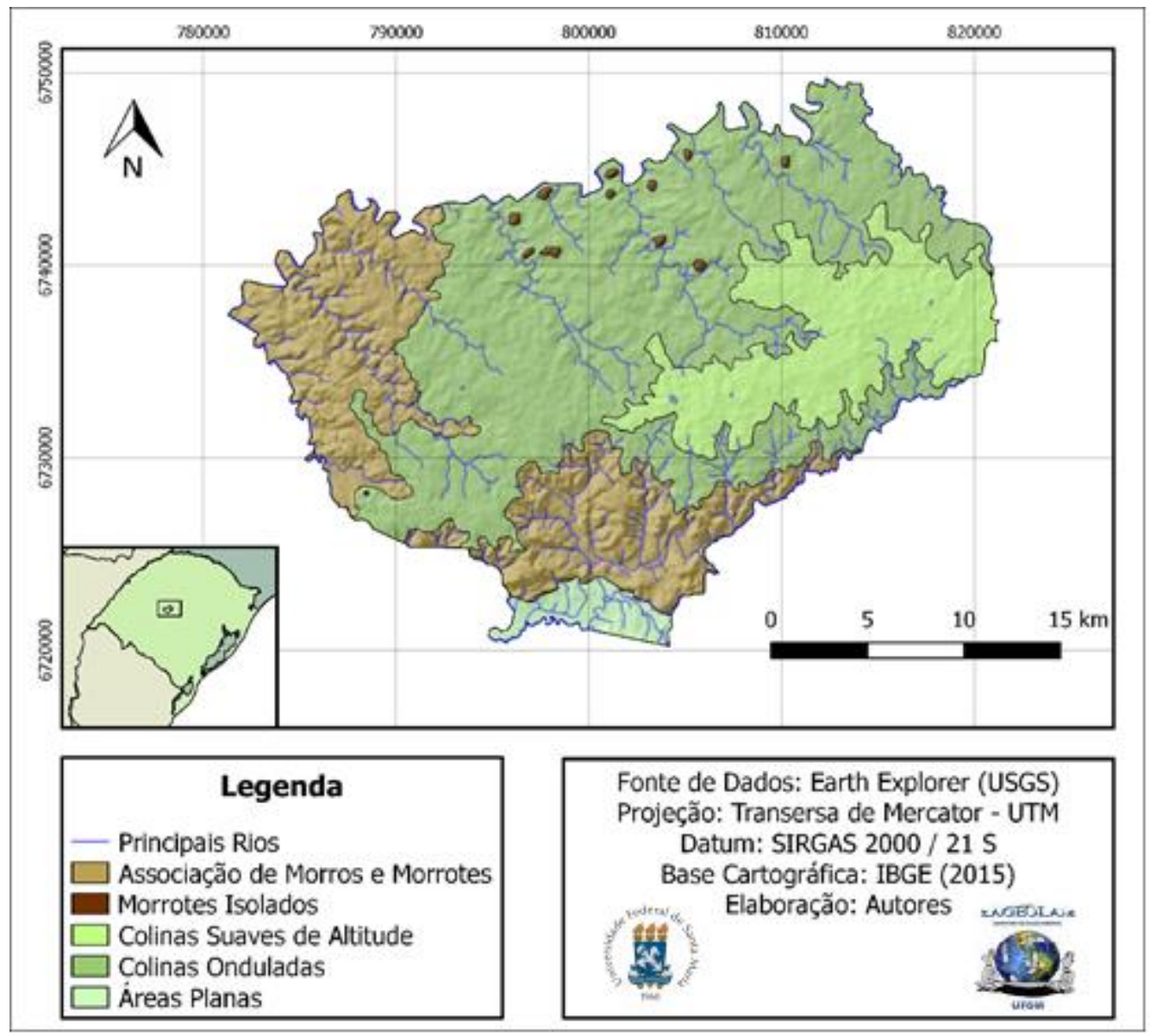

As Áreas Planas constituem $17,625 \mathrm{~km}^{2}$ e caracterizam-se por serem localizadas em altitudes inferiores a 150 metros com declividades menores que $2 \%$. Ocorrem em 2,63\% na área do município associadas as planícies de inundação e as áreas próximas dos principais afluentes do Rio Ibicuí-Mirim.

As Colinas Suaves de Altitude representam 16,81\% do município são localizadas nas elevações topográficas superiores à 450 metros, mas com declividades entre 5 e 15\% do Centro para o Leste do município, compreendendo a compartimentação do Planalto das Missões. Nessa forma de relevo ocorrem processos de sulcos e ravinas.

Representando 53,31\% do total da área do município de São Martinho da Serra, as Colinas Onduladas é a forma de relevo com maior abrangência na área de estudo $\left(357,374 \mathrm{~km}^{2}\right)$. Destacam-se por terem declividades entre 5 e $15 \%$ e amplitudes ao redor de $60 \mathrm{~m}$ e altitudes principalmente na classe hipsométrica de 
350 a 450 metros bem distribuídas ao longo de todo território. Constituem interflúvios curtos e a mecanização da agricultura torna-se difícil.

A quarta forma de relevo é a Associação de Morros e Morrotes, são encontradas em 26,83\% da área total do município expresso em 179.750 km² apresentando um relevo com declividades superiores a $15 \%$ e amplitude altimétrica ao redor de $100 \mathrm{~m}$ e ocorrendo dominantemente nas altitudes entre 250 e 350 metros.

A forma de Morrotes Isolados corresponde apenas $0,42 \%$ do município, com $2.817 \mathrm{~km}^{2}$. Essa forma ocorre em altitudes superiores a 350 metros, declividades maiores que $15 \%$ e amplitudes próximas a 60 metros, são encontrados em sua maioria na porção norte do município. Não é encontrado a presença de morros no município, uma vez que o que caracteriza essa forma é a amplitude altimétrica superior a 100 metros, a qual não é encontrada na área de estudo.

Tabela 4 - Dados quantitativos referentes às formas de relevo do município

\begin{tabular}{lcc}
\hline Formas de Relevo & Área $\mathbf{( k m}^{\mathbf{2}} \mathbf{n}$ & Porcentagem (\%) \\
\hline Áreas Planas & 17.625 & 2,63 \\
Colinas Suaves de Altitude & 112.729 & 16,81 \\
Colinas Onduladas & 357.374 & 53,31 \\
Associação de Morros e Morrotes & 179.750 & 26,83 \\
Morros e Morrotes Isolados & 2.817 & 0,42 \\
\hline
\end{tabular}

\subsection{Elementos do Relevo}

Os elementos de relevo obtidos por classificação automatizada são apresentados na figura 8, sendo: plano, pico, crista, ressalto, crista secundária, encosta (vertente), fosso, vale, base da encosta, escavado. 
Como aponta a tabela 04, os elementos com maiores abrangências são, primeiramente, os vales que são tipicamente uma área de baixa altitude cercada por áreas mais altas associando-se a canais de drenagem, constituindo 153,136 $\mathrm{km}^{2}$ e $22,84 \%$ do território. As cristas, que são representadas por topo alongados, compõem $18,58 \%$, as encostas ou vertentes $17,82 \%$ e cristas secundárias $(14,87 \%)$, formando o relevo com forma de colinas.

No relevo de colinas, as vertentes são o elemento mais importante e as cristas e vales são largos, sendo comuns a presença de cristas secundárias (Figura 10). Ocorrem, também, elementos do tipo escavado, o que forma o entalhamento nas vertentes.

Nas colinas suaves, o elemento de base de encosta é comparativamente mais importante, enquanto, nas formas definidas como áreas planas, os elementos plano e base de encosta são mais comuns. O elemento plano ocupa menos de $1 \%$ e é encontrado quase em sua totalidade no extremo sul do município.

No relevo de morros e morrotes os elementos vales e cristas são, relativamente, mais significativos e as vertentes são curtas. Os elementos de fosso estão associados aos vales mais profundos e os picos a topos de morros. 
16 | Suscetibilidade magnética na caracterização da variabilidade espacial...

Tabela 5 - Dados quantitativos dos elementos do relevo

\begin{tabular}{|c|c|c|c|}
\hline Elementos & Área em km² & Porcentagem (\%) & Representação \\
\hline Plano & 5,766 & 0,86 & \\
\hline Pico & 36,424 & 5,43 & \\
\hline Crista & 124,518 & 18,58 & \\
\hline Ressalto & 3,351 & 0,50 & \\
\hline Crista Secundária & 99,724 & 14,87 & \\
\hline Encosta & 119,480 & 17,82 & \\
\hline Escavado & 88,843 & 13,24 & \\
\hline Base de Encosta & 15,793 & 2,36 & \\
\hline Vales & 153,136 & 22,84 & \\
\hline Fosso & 23,524 & 3,50 & \\
\hline
\end{tabular}


Figura 8 - Mapa dos elementos do relevo de São Martinho da Serra - RS

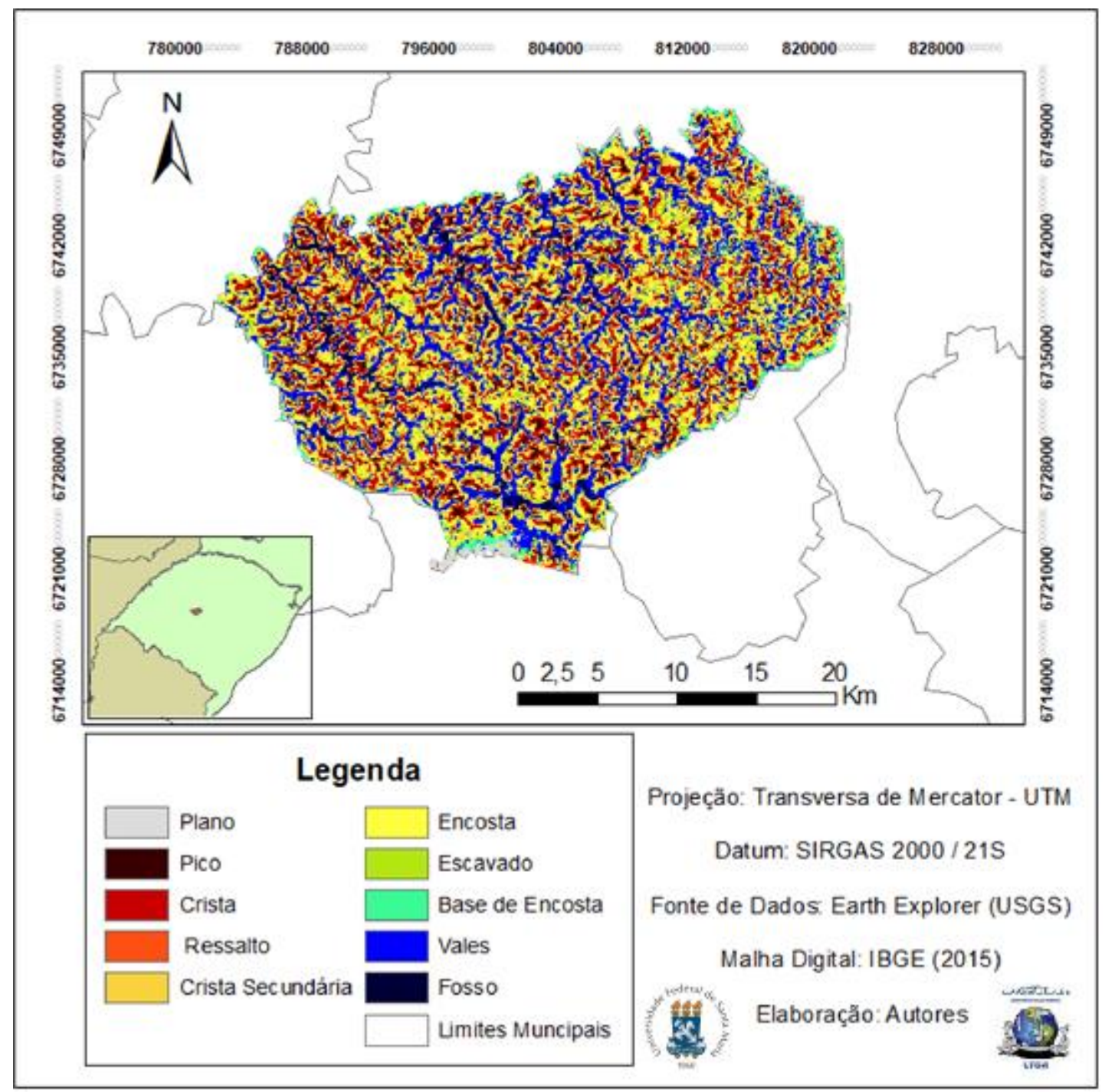

A Figura 9 compõe 3 recortes de imagens de satélite em que os elementos do relevo estão representados. No recorte A da figura, observa-se os elementos em uma área com relevo de colinas suaves de altitude. No recorte $B$, observa-se a distribuição dos elementos na passagem do relevo de colinas onduladas para o relevo de associação de morros e morrotes. E o recorte $C$, apresenta uma situação de distribuição de elementos na área de morros e morrotes. 
Figura 9 - Imagens via satélite representando os elementos do relevo de São Martinho da Serra - RS

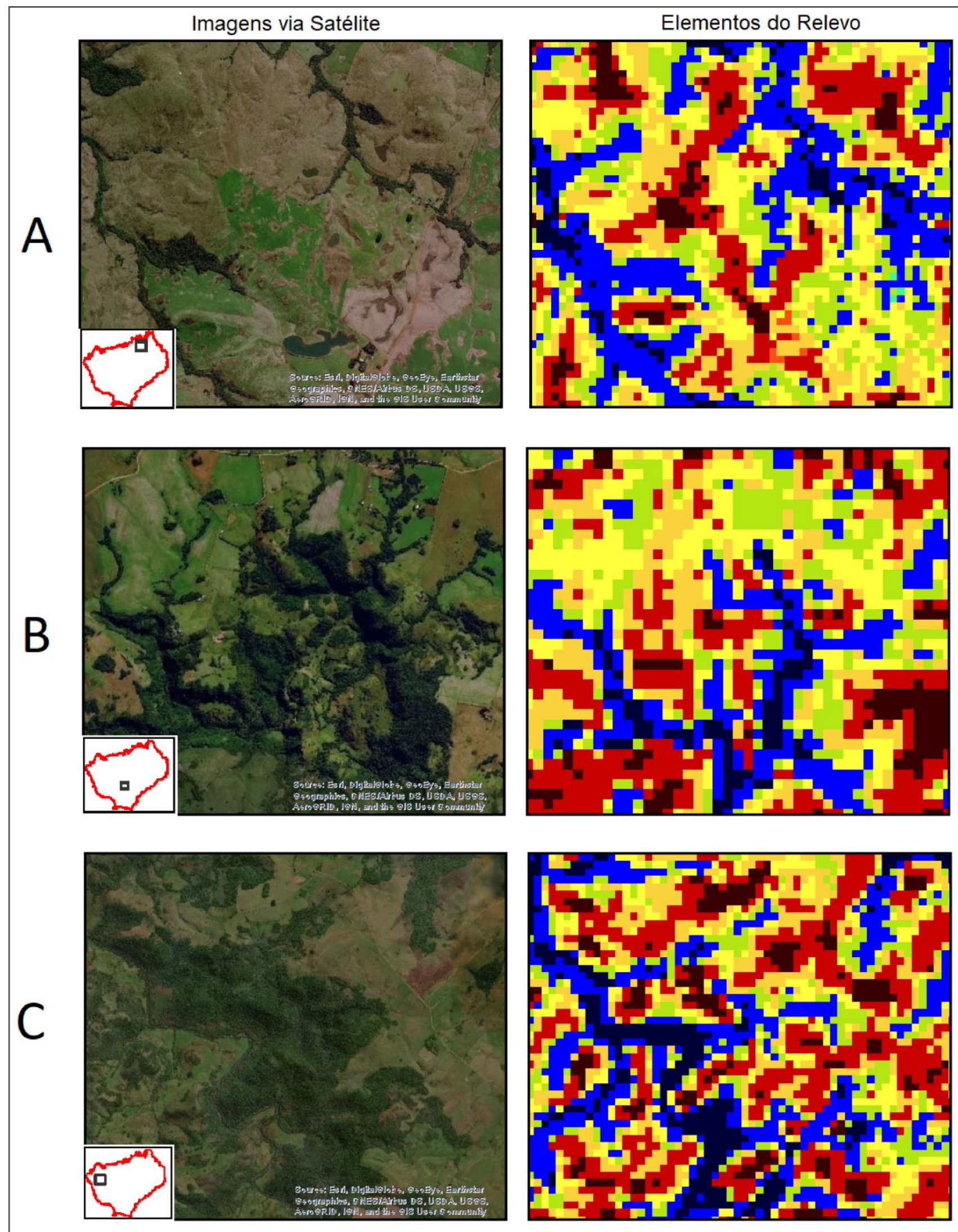

Elaboração: Autores 


\subsection{Formas das Vertentes}

A relação entre os atributos topográficos das vertentes como o perfil e o plano de curvatura, permitiu identificar 4 unidades geomorfométricas de São Martinho da Serra (Figura 10).

A Unidade I é caracterizada por ter perfil convexo e plano convergente com baixa ocorrência no município. É presente em canais de drenagens das áreas planas do município e nas colinas suaves, quando ocorridas nas vertentes são classificadas como coletoras de água.

Figura 10 - Mapa das Unidades Geomorfométricas de São Martinho da Serra - RS
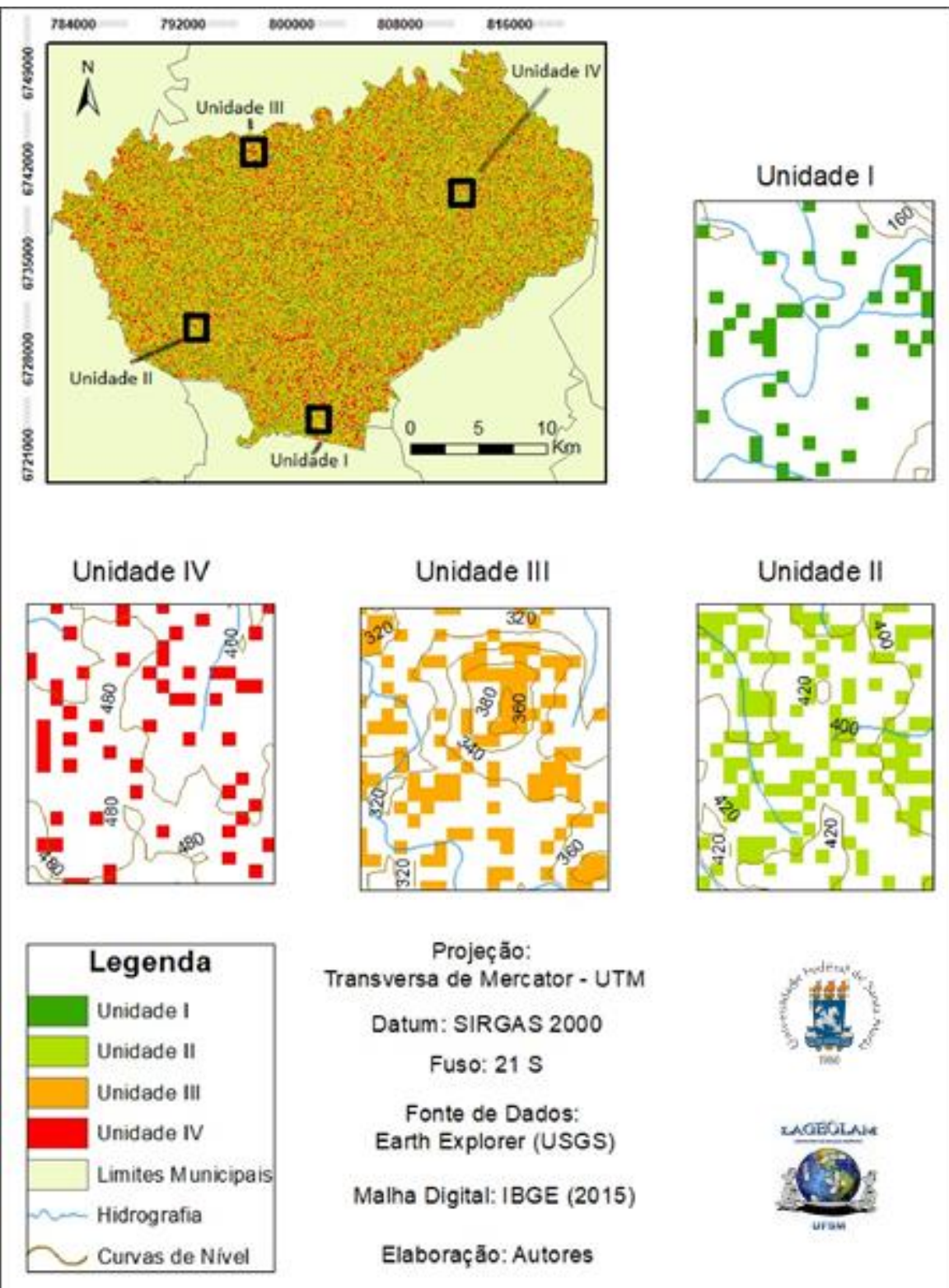

Ci. e Nat., Santa Maria, v.43, e49, 2021 
As vertentes com perfil côncavo e plano convergente representam a Unidade Il e que há maior abrangência na área de estudo. Podem gerar áreas alagadiças pois concentram o fluxo hídrico, estando associadas a nascentes em relevo de colinas suaves e canais no relevo de áreas planas. Essa unidade também pode constituir os vales nas áreas de relevo de morros e morrotes.

Por sua vez, a Unidade III é convexa-divergente e ocorre formando interflúvios nas áreas de colinas, planície de inundação nas áreas de relevo plano e constitui porções de topo de morros, morrotes e colinas onduladas.

E a última unidade, IV, destaca-se por ter perfil côncavo e plano divergente, resultando em dissipação do fluxo na porção mais central e maior velocidade de escoamento com dispersão de energia na porção mais superior da vertente. Essa unidade é presente em áreas de colinas suaves de maiores altitudes.

Tabela 6 - Quantificação das Unidades Geomorfométricas de São Martinho da Serra

\begin{tabular}{|c|c|c|c|c|c|}
\hline Unidades & Perfil & Plano & Área em km² & Porcentagem (\%) & Representação \\
\hline 1 & Convexo & Convergente & 90,952 & 13,92 & \\
\hline II & Côncavo & Convergente & 234,594 & 35,86 & \\
\hline III & Convexo & Divergente & 227,973 & 34,86 & \\
\hline IV & Côncavo & Divergente & 100,41 & 15,35 & \\
\hline
\end{tabular}

A tabela 5 apresenta maiores detalhes quanto a espacialização das Unidades Geomorfométricas no município e também representa as formas das vertentes com figuras de indicação do fluxo superficial da água adaptado de Hugget (1975). 


\section{CONSIDERAÇÕES FINAIS}

Os estudos de relevo representam importantes fatores condicionantes aos processos de dinâmicas superficiais, permitindo, deste modo, levantamentos fundamentais na definição de planejamento ambiental e ordenamento territorial.

A utilização de Sistemas de Informação Geográfica e a representação da superfície terrestre na forma de modelos numéricos digitais possibilitou a quantificação do relevo utilizando equações. As informações quantitativas apoiam a interpretação e identificação das formas de modelagem de relevo, evidenciando que o mapeamento e a análise do processo podem ser usados para dados qualitativos e quantitativos sobre formas de relevo e elementos de relevo.

A análise automatizada definiu as formas de relevo pela amplitude e declividade, os elementos de relevo pelas diferentes posições topográficas entre pixels através da técnica de identificar similaridade textural do MDE, que consiste na análise do nível de cinza de uma célula central e as suas vizinhas, portanto quando a célula central obtiver valor igual assuma o valor " 0 ", quando assumir valor maior considera-se o valor de "1", e quando menor representa valores menores que "-1", e a forma das vertentes pela análise no plano e perfil de curvatura.

Considera-se que a metodologia empregada para compartimentação do relevo através da utilização de geotecnologias se mostrou eficaz, uma vez que seus resultados foram comprovados em campo, constituindo um método prático, eficiente e com baixo custo que permite indicar áreas mais suscetíveis à ocorrência de processos superficiais como erosão e movimentos de massa. 


\section{AGRADECIMENTOS}

Agradece-se o apoio financeiro da Fundação de Amparo à Pesquisa do Estado do Rio Grande do Sul (FAPERGS) e do Conselho Nacional de Desenvolvimento Científico e Tecnológico (CNPQ).

\section{REFERÊNCIAS}

BAUERMANN, S. G., MACEDO, R. B., BeHLING, H., PILLAR, V. D. P., \& Neves, P. C. P. D. (2008). Dinâmicas vegetacionais, climáticas e do fogo com base em palinologia e análise multivariada no quaternário tardio do Sul do Brasil. Revista brasileira de paleontologia. Rio de Janeiro, RJ. Vol. 11, n. 2 (mai./ago. 2008), p. 87-96.

BORTOLINI, W, SILVEIRA, CT, SILVEIRA, R.M.P, 2017. Emprego de técnicas geomorfométricas na identificação de padrões de relevo. Revista Ra'e Ga 41, 131-150. Disponível: http:// dx.doi: 10.5380/raega.v41i0.51724. Acesso: 23 jan. 2017.

CASSETI, V. Ambiente e Apropriação do Relevo. São Paulo: Contexto, 1991. 147 p.

CHRISTOFOLETTI, A. Geomorfologia Fluvial. São Paulo: Edgard Blücher, 1980. 313 p.

DE MELO, F.P., MELO, R., ROSS, J. L. S. Modelagem de Geoformas para mitigação do risco geoambiental em Garanhuns - PE." Acta geográfica 10.22 (2016): 87-105.

ESRI - Enviromental Systems Research Institute. ArcGIS Desktop help. Redlands, 2012. Disponível em: http://resources.arcgis.com.

FURLAN, A.R., DIAS, D.F., TRENTIN, R., ROBAINA, L.E.S., 2018 a. Identificação das unidades geomorfométricas da bacia hidrográfica do arroio Carijinho, Rio Grande do Sul, Brasil. Revista Brasileira de Geomorfologia (Online) 19, 807-820. Disponível: http://dx.doi.org/10.20502/rbg.v19i4.1377 Acesso: 10 fev. 2019.

FURLAN, A.R., TRENTIN, R., ROBAINA, L. E. S., 2018 b. Classificação dos elementos do relevo a partir da metodologia dos geomorphons na bacia hidrográfica do rio Apuaê-Mirim, RS. Boletim Geográfico do Rio Grande do Sul 32, 27-45.

Hasenack, H.; Weber, E.(org.) Base cartográfica vetorial contínua do Rio Grande do Sul - escala 1:50.000. Porto Alegre: UFRGS Centro de Ecologia. 2010. 1 DVD-ROM. (Série Geoprocessamento n.3). ISBN 978-85-63483-00-5 (livreto) e ISBN 978-85-63843-01-2 (DVD).

HUGGET, R. J. Soil Landscape Systems: A model of soil genesis. Geoderma, v.13, p. 1-22, 1975. 
IBGE - INSTITUTO BRASILEIRO DE GEOGRAFIA E ESTATÍSTICA. Malha Municipal do ano de 2015. Disponível em: <http://mapas.ibge.gov.br/bases-e-referenciais/basescartograficas/malhasdigitais>. Acesso em: 18 de agosto de 2018.

IPT. Mapeamento geomorfológico do Estado de São Paulo. São Paulo. Escala 1:500.000. (IPT publicações, 1183) 1981.

JASIEWICZ, J.; STEPINSKI, T. F. Geomorphons a Pattern Recognition Approach to Classification and Mapping of Landforms. Geomorphology, 182. 2013. Pag. 147-156

LANA, C. E.; ALVES, J. M. de P.; CASTRO, P.T.A. Análise Morfométrica da Bacia do Rio do Tanque, MG-BRASIL. REM. Ouro Preto-MG, 2001. Revista Escola de Minas Vol 54(2), p. 121-126.

LANGE, G. F.; SILVEIRA, C. T. da. Mapeamento geomorfométrico da bacia hidrográfica do Zendron, Blumenau - SC. In: Anais do XVI Simpósio Brasileiro de Geografia Física Aplicada, Teresina - Pl, p. 854-862, 2015.

MELO, F. P. de Risco ambiental e ordenamento do território em Garanhuns-PE / Felippe Pessoa de Melo; orientadora Rosemeri Melo e Souza. - São Cristóvão, 2016. 248 f. : il. Tese (Doutorado em Geografia) - Universidade Federal de Sergipe, 2016.

MINÁR, J.; EVANS, I. S. Elementary forms for land surface segmentation: the theoretical basis of terrain analysis and geomorphological mapping. Geomorphology 95 (3-4), 236-259, 2008.

NIMMER, E. Clima. Rio de Janeiro. In: IBGE. Geografia do Brasil: Região Sul, 1977. p.35-79.

QGIS Development Team, (2014). 'QGIS Geographic Information System'. Open Source Geospatial Foundation Project. Disponível em: http://qgis.osgeo.org/en/site/

RADEMANN, L.K., DUTRA, D.S., ROBAINA, L.E.S., TRENTIN, R., 2019. Análise da rugosidade do relevo utilizando a ferramenta Focal Statistics no município de Canguçu, RS. Caderno de Geografia 29, 805-818. Disponível: https://doi.org/10.5752/P.2318-2962.2019v29n58p805-818. Acesso: 23 set. 2019.

ROBAINA, L.E. de S., TRENTIN, R., LAURENT, F., 2016. Compartimentação do estado do Rio Grande do Sul, Brasil, através do uso de geomorphons obtidos em classificação topográfica automatizada. Revista Brasileira de Geomorfologia (Online) 17, 287-298. Disponível: http://dx.doi.org/10.20502/rbg.v17i2.857 Acesso: 10 jan. 2019.

ROBAINA, L.E. de S., Trentin, R., Cristo, S.S.V., Sccoti, A.A.V., 2017. Application of the geomorphons to the landform classification in Tocantins state, Brazil. Revista Ra'E Ga 41, 37-48.

ROBAINA, L. E. de S.; VERDUM, R. Compartimentação Geomorfológica da Bacia Hidrográfica do Ibicuí, Rio Grande do Sul, Brasil: Revista Brasileira de Geomorfologia v. 2, p. 11-23, 2010.

ROSS, J.L.S., 2014. Geomorfologia: ambiente e planejamento, 9 ed. Contexto, São Paulo. 
SCOTTI, A. A. V.; ROBAINA, L. E. de S.; TRENTIN, R. Definição das 8 Unidades de Relevo da Bacia Hidrográfica do rio Ibicuí da Armada Sudoeste do Rio Grande do Sul. Caminhos de Geografia v. 16 , n. 54 Jun/2015 p. 35-48.

SEMA- Secretaria Estadual do Meio Ambiente. Bacia Hidrográfica do Ibicuí. Disponível em: http://www.sema.rs.gov.br/. Acesso em: 18 jan. de 2021.

SILVEIRA, R.P.M., SILVEIRA, C. T. Clasificación morfológica del relieve uruguayo basada en modelos digitales de elevación y técnicas morfométricas. Geografía y Sistemas de Información Geográfi ca. (GESIG-UNLU, Luján). Año 6, n. 6, Sección I: p.19-36, 2014.

SILVEIRA, R. M. P.; da SILVEIRA, C. T. Análise Digital de Relevo aplicada à cartografia geomorfológica da porção central da Serra do Mar Paranaense. Revista Brasileira de Geomorfologia v. 17, $n^{\circ} 4$ (2016)

SILVEIRA, C.T., SILVEIRA, R.M.P., TRENTIN, R., ROBAINA, L.E.S., 2018. Classificação automatizada de elementos de relevo no estado do Paraná (Brasil) por meio da aplicação da proposta dos geomorphons. Revista Brasileira de Geomorfologia (Online) 19, 33-57.

TRENTIN, R., ROBAINA, L.E.S., 2016. Classificação das unidades de relevo através de parâmetros geomorfométricos. Revista Mercator 15, 53-66.

TRENTIN, R., ROBAINA, L.E.S., 2018. Estudo dos elementos de relevo da bacia hidrográfica do rio Ibicuí com o uso do índice de posição topográfica Rev. Bras. Geomorfol. (Online), São Paulo, v.19, n.2, (Abr-Jun) p.423-431.

USGS - UNITED STATES GEOLOGICAL SURVEY. Shuttle Radar Topography Mission. Disponível em: http://srtm.usgs.gov/. Acesso em: 12 de julho de 2018

VELOSO, A.J.G. Importância do Estudo das Vertentes. GEOgraphia. V.8, n.8, 2002.

WILDNER, Wilson; RAMGRAG, Gilberto Emilio; LOPES Ricardo da Cunha; IGLESIAS, Carlos Moacyr Fontoura. Mapa Geológico do Estado do Rio Grande do Sul. Escala 1:750000. CPRM, Serviço Geológico do Brasil. Porto Alegre, RS. 2006.

\section{Contribuição de autoria}

\section{1 - Antonio Von Ende Dotto}

Acadêmico do Bacharelado em Geografia dottovon@gmail.com - https://orcid.org/0000-0002-3095-4679 Contribuição: Conceituação, Curadoria de Dados, Visualização, Análise Formal, Escrita Primeira Redação 


\section{2 - Luís Eduardo de Souza Robaina}

Pós-Doutor em Geociências

lesrobaina@yahoo.com.br- https://orcid.org/0000-0002-2390-6417

Contribuição: Curadoria de Dados, Visualização, Escrita - Revisão e Edição

\section{Como citar este artigo}

DOTTO, A. V. E.; ROBAINA, L. E. S. Identificação e Classificação do relevo do município de São Martinho da Serra - RS. Ciência e Natura, Santa Maria, v. 43, e49, p. 1-25, 2021. DOI 10.5902/2179460X42781. Disponível em: https://doi.org/10.5902/2179460X42781. Acesso em: dia mês abreviado. ano. 